\title{
Coping Strategies among Youth of Professional Colleges
}

\author{
Dr. K. N. Ranbhare' ${ }^{1}$, Supriya Mangaonkar ${ }^{2}$ \\ ${ }^{1}$ Faculty, ${ }^{2}$ Research Scholar \\ 1,2Department of Social Work
}

${ }^{1,2}$ Chhatrapati Shahu Institute of Business Education and Research, Kolhapur, Maharashtra, India

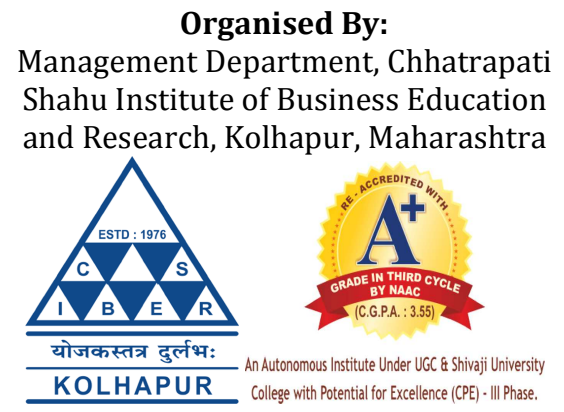

How to cite this paper: Dr. K. N. Ranbhare | Supriya Mangaonkar "Coping Strategies among Youth of Professional Colleges" Published in International Journal of Trend in Scientific Research and Development (ijtsrd), ISSN: 2456-6470, Special Issue | Fostering Innovation, Integration and Inclusion Through Interdisciplinary

Practices in Management, March 2019, pp.32-34, URL: https://www.ijtsrd.c om/papers/ijtsrd23 056.pdf

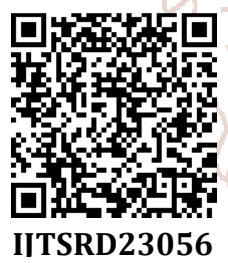

\section{INTRODUCTION}

Coping is viewed as the covert and overt behavior by which the organism actively prevents, removes or circumvents stress inducing circumstances (McGrath, 1970)

Folkman and Lazarus have defined coping as a person's constantly changing cognitive and behavioral efforts to manage an encounter appraised as stressful

Coping Strategy is a behavior that helps us to function better in a given situation. The Psychological coping mechanisms are commonly termed coping strategies or coping skills.

Coping strategies refer to the specific efforts, both behavioral and psychological, that people employ to master, tolerate, reduce, or minimize stressful events.

ABSTRACT
Medical and Engineering students experience stress from their 1st academic year. There are many studies which have assessed stress level of students but ery few studies covered how they prevent or cope up with the stress. Hence this was attempted with an objective to understand the influence of Gender Ancome and Type of Family on coping strategies among mamedical and engineering students in Kolhapur city. Proportionate Random pling method was used to select respondents. Data was collected by using Whereas, gender, family income, type of family didn't have significant relation with coping strategies.

KEYWORDS:-Information Technology (IT), Electronic Voting Machine (EVM), Software, None of the above (NOTA), Media

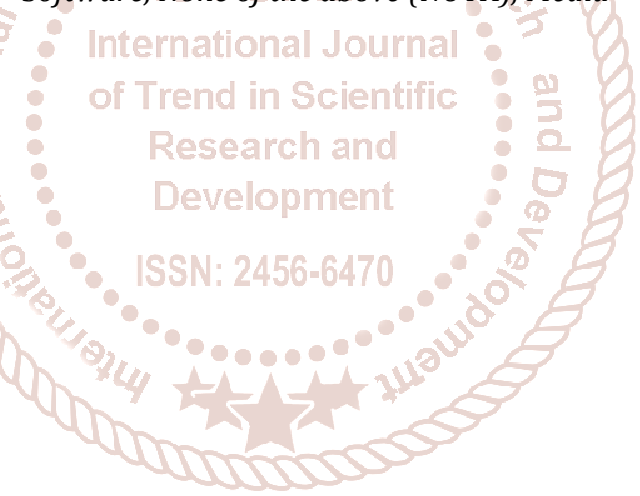

Schregardus (1976) proposed two major styles of coping namely repression and sensitization. He also found that patterns of defensive style were related to the perception \& experiences of stress and to subsequent patterns of coping \& adjustment.

Stressful encounters like beginning of college, getting a job, life changes, daily hassles, catastrophic events, economic and social condition etc. each of these events represent a significant change in a person's life. A life change can happen at any part during the life span (positive or negative) and can be predictable or unexpected (Holmes \& Raha 1967).

A large body of research has accumulated in the past three decades demonstrating that coping is a crucial determinant of psychological well-being with its outcome depending largely on the types of strategies employed (Liu Z. A ,2008, Zhang et al, 2008) 
International Journal of Trend in Scientific Research and Development (IJTSRD) @ www.ijtsrd.com eISSN: 2456-6470

Studies have proved that higher levels of coping skill is associated with higher levels of positive adjustment and lower level stress (Cheng C \& Cheung MWs,2005) and symptoms of burnout. (Gan Y et al 2007).

Studies also have been reported on "Stress and coping strategies of students in a medical faculty in Malaysia" (Sami Abdo Radman et.al.2011), stress \& coping strategies among undergraduate medical students (Samira S. Bamuhair, et.al. 2015), "Hong Kong baccalaureate nursing students' stress and their coping strategies in clinical practice" (Chan CK, So W K, and Fong DY (2009), Health impact on nursing students against stress, coping way and social support (Luo \& Wang, 2009).

Students of professional colleges have to confront various stressors such as academic pressures, work over load and issues pertaining to professional competence. Students also encounter doubts about one's clinical or technical ability, faculty relations, mistreatment \& uncertainties about professional images etc.

Therefore the current study focuses on how the students cope up when they confront difficult or stressful events in their lives. Hence the present study aims to examine the coping strategy of Medical and Engineering students in Kolhapur city.

\section{Objectives:}

$>$ To study the demographic background of the respondents.

$>$ To find out the coping strategies of Engineering and Medical students.

$>$ To understand the influence of Gender, Academic stream, income and Type of Family on coping strategies.

\section{Hypothesis:}

Gender, type of family, academic stream \& coping strategies of the respondents are independent of each other

\section{Research Methodology}

Universe of the Study: The universe of the study covers students studying in the $\mathbf{1}^{\text {st }}$ year in selected professional colleges (Medical \& Engineering) in Kolhapur city.

Sample Design: Researcher selected One Engineering and One Medical College in Kolhapur city. Selected Engineering college has a strength of 150 in I year and Medical students are 100 in I year. Samples were collected by using proportionate Random Sampling method. Hence 60 students from Engineering stream and 40 students from Medical stream were selected. However due to some reasons 4 students could not complete the questionnaire, Hence the total sample constituted to 96 respondents.

\section{Tools of Data Collection and Measures:}

Data were collected by a Questionnaire. A multidimensional coping scale (Carver, 2013) with 15 subscales each consisting of four items focusing on distinct aspects of coping was used for the study. The items are scored on a 4-point scale, with scores ranging from 1 to 4 . Items are summed to produce scale scores, with higher scores reflecting greater use of a particular coping strategy.

\section{Results:}

The Table No.1 discloses the Mean and Standard Deviation for coping strategies. The overall Mean score for coping seems to be low among the respondents (2.39).

Positive Reinterpretation \& Growth coping strategy shows highest Mean score (3.09), followed by other strategies like Planning (2.91) \& Active coping (11.05). It is noteworthy that our respondents are not inclined towards substance use (1.20) \& hence it depicts least Mean score followed by behavioral disengagement (2.07).

Engineering students (47.91\%) have low coping level as compared to medical students $(16.67 \%)$. Female students $(21.88 \%)$ have high coping level than male students (13.55 $\%)$.

Except Academic stream no other independent variables like Gender, Type of family and family income has significant relationship with coping strategies among youth. It may be because medical students are exposed to the dynamics of human behavior, the issues related to the Human biology etc. Medical field deals with Human-being and therefore the student of medical streams get sensitized to the problems faced by various people \& ultimately they learn various ways of coping. Engineering students are exposed to technical kind of work \& may take time to cope up with emotions \& behavior of their personal and academic life.

\section{Conclusion \& Suggestions:}

The overall coping strategies seem to be low among respondents. The findings point towards the crucial need for stress management programs for enhancing psychological well-being among the students studying in professional colleges. There should be appropriate support services for the students in collaboration with the college faculty \& the staff.

Findings of this study led us to conclude that the coping is higher among the female students than the male students. The coping level is high among the medical student as compared to engineering students. Student support should be available in the form of mentoring \& guidance to help in coping with stress \& to educate the students about unhealthy consequences of stress. College should appoint a wellqualified counselor to guide students in a proper way in order to nurture mental hygiene among students.

\section{References:}

[1] Carver, C. S. (2013). COPE Inventory. Measurement Instrument Database for the Social Science. http://www.midss.org

[2] Chan CK, So WK, and Fong DY," Hong Kong baccalaureate nursing students' stress and their coping strategies in clinical practice", Journal of Professional Nursing, Sept.-Oct. 2009,Vol.25(5):307-13.

[3] Cheng C, Cheung MW. Cognitive processes underlying coping flexibility: Differentiation and integration. J Pers 2005;73:859-86

[4] Dewe. p. Guest. D \& William R (1979) methods of coping with work related stress. In C Mackay. \& T. Cox (Eds). Response to stress: Occupational Aspects. London: IPC Science \& Technology Press. 
International Journal of Trend in Scientific Research and Development (IJTSRD) @ www.ijtsrd.com eISSN: 2456-6470

[5] Gan Y, Shang J, Zhang Y. Coping flexibility and locus of control as predictors of burnout among Chinese college students. Soc Behav Pers 2007; 35:1087-98.

[6] Folkman S, Moskowitz JT. Coping: Pitfalls and promise. Annu Rev Psychol 2004; 55:745-74. 」

[7] Liu Z. A perceived stress mediating model study about problem-focused styles of coping in university students affect mental health. Chin J Clin Psychol 2008; 16:170-2.

[8] Luo Y, Wang H,“Correlation research on psychological health impact on nursing students against stress, coping way and social support", Nurse Education Today, Jan.2009;Vol.29(1):58.

[9] Mc Grath. J (1970). Social \& Psychological Factors in stress. New York: Holt, Reinehart \& Winston

[10] Samira S. Bamuhair, et.al. titled "Sources of stress \& coping strategies among undergraduate medical students enrolled in a problem-based learning curriculum" (Journal of Biomedical Education Volume 2015)

[11] Sami Abdo Radman Al-Dubai, Redhwan Ahmed AlNaggar, Mustafa Ahmed Alshagga and Krishna Gopal Rampal, "Stress and coping strategies of students in a medical faculty in Malaysia", Malaysia Journal of Medical Science, Jul- Sept.2011; Vol.18 (3):57-64.

[12] Schregardus. D .j (1976). A study of defensive style and its interaction with perception and experience of stress. Dissertation Abstracts international 400.

[13] Zhang T, Kang X, Zhang F. Study on the relationship of life events, coping styles and negative emotion among college students. J Agric Univ Hebei 2008; 10:449-52.
Table No. I Mean and Standard Deviation for Coping Strategies

\begin{tabular}{|c|c|c|}
\hline Coping Strategies & Mean & SD \\
\hline Positive Reinterpretation and Growth & 3.09 & 0.65 \\
\hline Mental Disengagement & 2.30 & 0.57 \\
\hline Focus on and Venting of Emotions & 2.28 & 0.65 \\
\hline Use of Instrumental Social Support & 2.52 & 0.67 \\
\hline Active Coping & 2.76 & 0.59 \\
\hline Denial & 2.10 & 0.57 \\
\hline Religious Coping & 2.47 & 0.80 \\
\hline Humor & 2.08 & 0.70 \\
\hline Behavioral Disengagement & 2.07 & 0.68 \\
\hline Restraint & 2.54 & 0.63 \\
\hline Use of Emotional Social Support & 2.28 & 0.64 \\
\hline Substance Use & 1.20 & 0.47 \\
\hline Acceptance & 2.77 & 0.62 \\
\hline Suppression of Competing Activities & 2.53 & 0.65 \\
\hline Planning & 2.91 & 0.65 \\
\hline Total & 2.39 & 0.35 \\
\hline
\end{tabular}

Table No. II Chi-Square values for Independent variables \& Coping strategies Independent Variables $\quad$ X 2 Value

\begin{tabular}{|l|c|c|}
\hline 1 & Gender & 0.25 \\
\hline 2 & Academic stream & 18.11 \\
\hline 3 & Type of Family & 1.15 \\
\hline 4 & Family Income & 1.61 \\
\hline
\end{tabular}

Copyright (C) 2019 by author(s) and International Journal of Trend in Scientific Research and Development

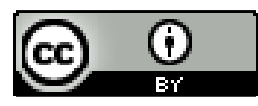
Journal. This is an Open Access article distributed under the terms of the Creative Commons Attribution License (CC BY 4.0) nt (http://creativecommons.org/licenses/by/4.0) 